\title{
Development Cooperation as a Knowledge Creation Process: Rhythmanalytical Approach to a Capacity-Building Project in Zanzibar
}

\author{
Minna-Liina Ojala ${ }^{1}$ (D) Lauri Hooli $^{2}$ (D)
}

Accepted: 11 February 2021 / Published online: 5 March 2021

(c) The Author(s) 2021

\begin{abstract}
In development cooperation, the ideas of material support and instructive teaching have increasingly given way to those of reciprocal collaboration and non-material support. In this research, we explore the potential of rhythmanalysis as an approach to studying complex knowledge creation processes in an international development cooperation project. The Zan-SDI project aimed to enhance the geospatial infrastructure in Zanzibar through cooperation between Finnish and Zanzibarian experts. Our rhythmanalysis shows that knowledge creation in the everyday practices of development cooperation is extremely vulnerable to various distractions on multiple spatio-temporal scales. Continuous learning and efforts are required to sustain the project ensemble and knowledge creation. Although new partnerships and interorganisational collaboration are a source of novelty and innovation, much of their potential remains unrealised without intensive long-term engagement, possibilities to quickly reform the project scheme, and a sufficient combination of financial, material and non-material support.
\end{abstract}

Keywords Development cooperation · Knowledge creation · Rhythmanalysis · Ethnography

\section{Résumé}

Dans la coopération au développement, les idées de support matériel et d'enseignement instructif ont cédé place aux idées de collaboration réciproque et support non-matériel. Dans cet étude, nous explorons le potentiel du « rythmanalyse » (en anglais : ryth-

Lauri Hooli

Lauri.hooli@utu.fi

Minna-Liina Ojala

minna-liina.ojala@utu.fi

1 Department of Marketing and International Business, University of Turku, 20014 Turku, Finland

2 Department of Geography and Geology, University of Turku, 20014 Turku, Finland 
manalysis), une approche qui permet d'étudier le processus de création de connaissances complexes au sein d'un projet de coopération au développement international. Le projet Zan-SDI visait à améliorer la structure géospatiale au Zanzibar à travers la coopération d'experts Zanzibariens et Finlandais. Notre rythmoanalyse montre que la création des connaissances dans les pratiques quotidiennes de la coopération au développement est extrêmement vulnérable à plusieurs distractions spatiotemporelles. Des efforts soutenus et un apprentissage continu sont requis afin de soutenir le projet dans son ensemble et la création de connaissances. Même si les nouveaux partenariats et la collaboration inter-organisationnelle sont une source de nouveautés et d'innovation, la plupart de leur potentiel reste sans se réaliser a moins qu'il y ait de l'engagement à longue durée, la possibilité de rapidement reformer le schéma du projet, et une combinaison de support financier, matériel et non-matériel suffisante.

\section{Introduction}

Contemporary development cooperation projects are increasingly based on capacity development and knowledge creation processes between different actors from the Global North and South. These processes are also an integral and explicit part of the United Nations' Sustainable Development Goals (SDG), where the focus is shifting from special development professionals towards cooperation in various sectoral projects (Janus et al. 2015). In expert-expert collaboration, the objective is to foster local living conditions and sustainable development by enhancing mutual learning, local capabilities and sociotechnical skills to use new analytical knowledge and advanced technological equipment (Vallejo and Wehn 2016; Horner and Hulme 2019; Lewis 2019). In this article, we scrutinise the knowledge creation processes in the Zan-SDI capacity-building project (National Spatial Data Infrastructure for Integrated Coastal and Marine Spatial Planning in Zanzibar) implemented in Zanzibar, Tanzania, in 2016-2018.

Development cooperation is a controversial, complex and multipurpose sociopolitical concept that is in constant flux. Its ultimate goal is not only to foster the social, economic, and environmental development of certain locations and enhance the capacity of local stakeholders, but also to bring mutual benefits for its providers (Powell and Cummings 2019). Currently, the most common objectives are consistent with the SDGs aiming to 'end poverty, protect the planet, and ensure prosperity for all' (United Nations 2015). Earlier approaches in development cooperation were dominated by development professionals working in bilateral and multilateral projects and staying in their postings for several years (Walz and Ramachandren 2011). Currently, it generally involves specific project-based peer groups including bureaucracies, technical specialists and scientific experts from the donor and recipient countries (Gore 2013). The projects are a mix of actors from the Global North, who often have a high degree of analytical knowledge but a limited understanding of local socioeconomic development, and actors from the Global South, who may have less analytical knowledge but are solid experts on the local circumstances in their countries (Fejerskova et al. 2017). 
These newly emerging dynamics have increased the complexity of development cooperation. The fragmentation, diversification and proliferation of actors and the knowledge landscape have made the definition of international development and the subsequent impact much more intricate and difficult to evaluate (Lewis 2019). Knowledge, data and understanding about the nature and scope of activities accomplished under the label of development are sparse. Therefore, contemporary development research should constantly develop new interdisciplinary and in-depth research strategies to catch up with the changes and understand its knowledge creation processes (Olsen 2019).

Knowledge and its creation are fundamental parts of development dynamics and a core objective of various projects such as mitigating climate change, enhancing agricultural productivity and improving public administration (Jones et al. 2013). Knowledge can be considered as a set of shared beliefs that are constructed through social interaction and embedded in the social contexts and interactions in which that knowledge is created (Nonaka and Takeuchi 1995; see also Lefebvre 1991). Knowledge is created in concrete places in local social environments and cultures, under broader economic and political processes (e.g., Livingstone 2003, p. 4; Lefebvre 1991, 2004).

The processes of knowledge creation are widely studied and increasingly understood in science (Popper 2005), the private sector (Little and Deokar 2016), art (Hautala 2015) and international projects (Flower et al. 2015). These processes have been researched mostly in urban centres (Gibson 2012; Grabher and Ibert 2014). Gradually, the scope has expanded towards the peripheries in the North (Gibson 2012; Glükler 2014; Ojala and Hautala 2019) but far less so in the South (Shearmur et al. 2016) and insufficiently as a part of development cooperation (Jauhiainen and Hooli 2019; Powell and Cummings 2019). Contrary to most of the knowledge creation processes in the Global North, those related to development cooperation vary widely at least in terms of power relationships, differing knowledge amongst actors, and financing (Janus et al. 2015).

To understand the procedural nature of knowledge creation in depth, the scholars of knowledge creation and organisational studies have called for a more nuanced and practice-based consideration of these processes (e.g., Hautala and Höyssä 2017; Ibert 2007; Schillings and van Wickeren 2015). Projects can be considered temporary organisations (e.g., Sydow and Braun 2018; Turner and Müller 2003), and the routines and practices in the organisations need to be understood as sensible (Strati 2007), embodied (Gärtner 2013; Viteritti 2013; Wright 2019), ambiguous, and situated in action (Feldman et al. 2016). Henri Lefebvre's (2004) work on rhythms resonates with these ideas, and rhythmanalysis is considered to offer a novel approach to analysing complex processes (e.g., Edensor 2010a; Frank 2019; Lyon 2019). Rhythmanalysis has been used to scrutinise various spatio-temporal occurrences and power modalities in everyday life. However, it is only rarely applied to the study of knowledge creation processes (Ojala and Hautala 2019) and never to development cooperation. Therefore, in this study, we apply the rhythmanalytical methodology to complement the literature on knowledge creation processes and hopefully gain a deeper understanding of the processes involved in international development dynamics. 
This theoretical framework guided the empirical part of our study. We used data triangulation to scrutinise the changing development pattern from two different but interrelated dimensions: knowledge and the interplay of related actants. We engaged in a longitudinal and intensive ethnographic study of the Zan-SDI project in which corresponding experts from Zanzibar and Finland were engaged. Our research contributes to two perspectives of understanding knowledge creation processes in development cooperation projects. First, although contemporary development projects focus increasingly on knowledge creation processes between different actors, these processes have not been appropriately analysed (van Veen et al. 2013). By asking through what kinds of rhythms knowledge is created in the Zan-SDI project, our research increases the theoretical and empirical understanding of knowledge creation processes, especially in development cooperation. Second, we ask what opportunities and limitations rhythmanalysis has for scrutinising complex knowledge creation processes. In the next section, we review knowledge creation processes in development cooperation, and thereafter explain how we interpret Lefebvre's rhythmanalysis in the context of this study.

\section{Knowledge Creation Processes in Development Cooperation}

Foreign technology experts, with their expertise and knowledge, have had a central role in development assistance ever since the start of the modernisation era of development following the World Wars (Rocha 2013). Initially, the view was that omniscient experts from the Global North could simply transfer their (technical) knowledge to the Global South without the participation of local communities. This was closely related to the rational approach of knowledge transfer based on instructional teaching and material support (Bathelt and Henn 2014). In knowledge transfer, the movement of knowledge is considered an event rather than a process, meaning that it is possible to move knowledge almost like an object from one place to another without changing it or without the change being empirically scrutinised. The recent constructionist approach of knowledge creation challenges this and defines knowledge as a process that is an invisible part of fluid social practices (Ibert 2007). Knowledge developed in one context may not be suitable for social, economic, and environmental conditions elsewhere. Instead, it is created interactively and is partly tacit; it must be translated when used in different local and historical contexts (Ancori et al. 2000, p. 279).

Even today, foreign experts from the Global North most often contribute analytical knowledge to pursue specific sector goals in fields such as health, agriculture, energy or science (Jones et al. 2013). Analytical knowledge is based on systematic research and development activities and formal learning processes (Asheim and Coene 2006). It requires skilled and educated human resources and high-technological equipment. Analytical knowledge is universal and abstract and often codified into scientific formulas or laws (Nonaka and Takeuchi 1995, p. 59). Most of the time, project members work apart in their home locations and gather occasionally to achieve specific objectives. However, this dispersal hampers knowledge creation processes in a project, creates risks of misunderstanding and difficulties in 
coordination, and delays reactions to problems (Nguyen-Duc et al. 2015). Co-location and co-presence, on the contrary, are highly beneficial (Gertler 2003; Hautala 2018). Co-location increases the local buzz and intentional and spontaneous interaction amongst the project members (Bathelt et al. 2004). In co-presence, individuals experience each other, share, and are aware of the common understanding of the project, its objectives, and the operational means of achieving them (e.g., Grabher et al. 2018; Ojala and Hautala 2019). Although this joint understanding may be maintained in dispersion, it can only be created in co-present interaction (Hautala 2018).

Although actors from the Global South generally have less analytical knowledge, they are solid experts on their local socioeconomic contexts (Drucker 1993; Jauhiainen and Hooli 2019). Therefore, interaction between knowledge producers, appliers, and users in geographic proximity is obligatory for achieving successful knowledge creation processes (Ibert 2007, p. 106). Combined analytical and context-specific knowledge has a stronger influence on the project output than either of them alone (Parrilli and Heras 2016). Beyond the limited contextual understanding amongst experts from the Global North, a common challenge is that actors from the Global South often lack the absorptive capacity to utilise analytical knowledge handed down by foreign experts and may not have the resources to take advantage of the latest technological equipment (Cohen and Levinthal 1990; Hooli and Jauhiainen 2018). Therefore, the contextualisation of knowledge requires extra recognition of cognitive processes between various actors and their personal interpretations (Hautala and Jauhiainen 2014).

\section{Rhythmanalysing Zan-SDI}

\section{The Zan-SDI Project}

Zan-SDI was a development cooperation project between government and public sector institutions in Finland and Zanzibar. These two states differ significantly. Whilst Finland is a Northern welfare country with 5.5 million inhabitants and a large surface area of $338,450 \mathrm{~km}^{2}$, Zanzibar is a semiautonomous archipelago of the United Republic of Tanzania with its own constitution, government, and budget (see Fig. 1). Its surface area of $2,461 \mathrm{~km}^{2}$ is populated by over 1.3 million inhabitants. Zanzibar has a small GDP per capita of around EUR 780 in 2016, compared to Finland's GDP per capita of approximately EUR 39,000 in 2016 (UN 2019). The quality of democracy in Finland is ranked foremost internationally, and it is one of the most prosperous countries in the world in terms of standard of living, education and health. Zanzibar is amongst the least developed regions of the world and is described as an authoritarian regime. Development cooperation projects are an important part of the socioeconomic development of Zanzibar. Finland and Tanzania have a longstanding relationship in development assistance dating back to the 1960s, of which Zanzibar has been a specific beneficiary. For its part, Finland has emphasised its own areas of strength such as forestry, democracy, inclusive and transparent society, 


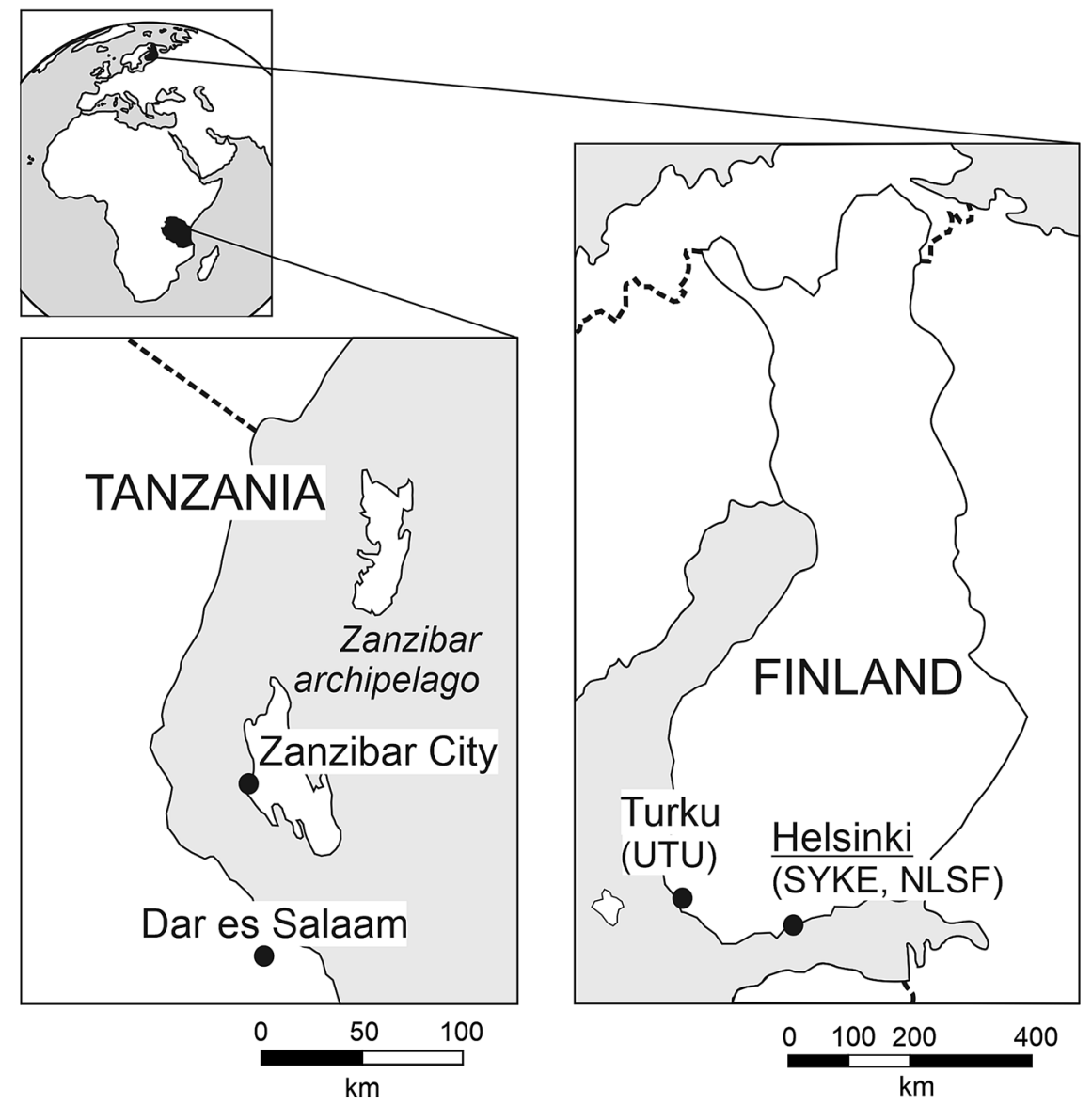

Fig. 1 Maps of Zanzibar and Finland showing the locations of partner organisations. All Zanzibarian organisations were located in Zanzibar City or nearby

and improving the performance of the public sector (Ministry for Foreign Affairs of Finland 2017).

The main objective of the Zan-SDI project was to improve the way geospatial information is used in regional planning in Zanzibar. The immediate objective was to enhance the capacity of the stakeholders to use effectively the National Spatial Data Infrastructure (NSDI) in integrated coastal and marine spatial planning (ZanSDI 2015, p. 13). A spatial data infrastructure can be defined as 'a framework of technologies, policies, and institutional arrangements that together facilitate the creation, exchange and use of geospatial data and related information resources across an information-sharing community' (ESRI 2010). It is about the efficient storing, sharing and reading of information. A functional NSDI and expertise in coastal and marine spatial planning are important issues all over the world, especially for 
archipelagos like Zanzibar, which are biodiversity hotspots and very vulnerable to climate change.

The Zan-SDI project was funded from the official development cooperation funds of the Ministry of Foreign Affairs of Finland and based on the Institutional Cooperation Instrument (ICI). ICI is a funding mechanism that supports governmental institutions participating in development cooperation. The idea is that capacity is best built when colleagues with similar tasks and responsibilities share their expertise and experience (ICI 2012). The overall budget of Zan-SDI was EUR 718,800, of which $69 \%$ was spent on personnel, travel and accommodation costs and per diem allowances of the Finnish Environment Institute (SYKE) and National Land Survey of Finland (NLSF); $15 \%$ on subcontracted assignments; and 13\% on travel, accommodation and per diem allowances of the partner organisations from Zanzibar (ZanSDI 2019, p. 16). Only 3\% was expended on fixed assets (mainly equipment) and administrative costs in Zanzibar.

The implementation of the project was divided into three distinct but complementary work packages (WP), each with its own expected objectives and results. WP1 aimed to increase the capacity for developing and maintaining the NSDI; WP2 aimed to enhance the capacity for ecosystem-based planning and the management of coastal zones, maritime activities, and the marine environment; and WP3 aimed to improve geospatial capacities at partner organisations. The main project partners were SYKE, NLSF, and the Zanzibar Commission of Lands (COLA). In practice, the peering organisations included two working groups from SYKE-the 'SDI group' working on WP1 with NLSF and the 'Marine group' working on WP2 - and seven governmental departments of Zanzibar, and the State University of Zanzibar (SUZA). Also, the Department of Geography and Geology from the University of Turku, Finland, was subcontracted to provide geospatial capacity building and training for WP3. Altogether, the Finnish partners visited Zanzibar 14 times, and the Zanzibarian partners visited Finland three times in varying group compositions.

\section{The Basis of Rhythmanalysis}

The take-home message from Lefebvre's work has been understanding space as socially produced, but rhythmanalysis highlights that our understanding of time ought to be challenged as well. Lefebvre (1991, p. 12, 2004) notes that the perception of time is affected by that of space, and vice versa. Therefore, space and time cannot be understood or experienced separately. Instead, together with energy, they merge into what Lefebvre (2004) terms as rhythms. Rhythmanalysis is an incomplete philosophical and methodological approach, and we contribute to its examination and development in this paper.

Rhythms do not exist without repetition, but no repetition is identical, because rhythms always include something new and unforeseen (Lefebvre 2004, p. 6). The same applies to (organisational) routines that simultaneously evoke stability and change (Feldman et al. 2016). Although seemingly monotonous, reproducing a routine - such as a meeting - is both an intentional and emergent accomplishment. The 
interface between organisational studies and rhythmanalysis is clear. However, for Lefebvre (2004), everything from more concrete phenomena to abstract ones, such as learning, is and has its own rhythm. Chen (2018, p. 45) explains that the fusion of mental, physical and social is possible because rhythm is both 'the effect and the agency of temporal-spatial arrangement.' Lyon (2019, p. 61) adds that this idea is based on Lefebvre's conception of the unity of body and mind.

Different rhythms form a 'tangled mess,' an ensemble of multiple rhythms to be scrutinised (Lefebvre 2004, p. 33). Lefebvre (2004, pp. 16, 67) offers preliminary concepts to describe the interaction of rhythms in an ensemble: polyrhythmia as the multiplicity of rhythms, eurhythmia as the harmony, arrhythmia as discordance, and isorhythmia as the equivalence of rhythms. Recently, these concepts have been applied to understand, for example, knowledge creation in a research project (Ojala and Hautala 2019) and learning in adult education (Alhadeff-Jones 2019). Based on these studies, it becomes clear that knowledge is created through the dynamic interaction of various rhythms, whilst the interaction forms its own 'knowledge creation rhythm' at the same time.

The interest of knowledge is emancipatory as the work of a rhythmanalyst is to trace and connect rhythms to the 'machinery' (re)producing them (Lefebvre 2004, p. 15). Syring's (2009) study illuminates this aspect well: a house-building project in Ecuador bundled together three men with different rhythms and strategies for livelihood. Albeit mutually beneficial, the construction site was also a site for conflict and frictions reflecting the inequality of global labour arrangements. For Lefebvre, bringing forth such personal experiences and moments could contribute to uniting humanity (Shields 1998, p. 62).

Even a mundane practice like walking has rhythmic dimensions that contribute to (re)producing places and time-spaces, or rhythms, whilst also being produced by them: walking may break conventions but is also regulated in multiple ways (Wunderlich 2008; Edensor 2010b). To understand what to emancipate, rhythmanalysis focuses on the lived experience and everyday life with its routines and their (re) production. Rhythms are 'grasped' by living them (Lefebvre 2004, pp. 47, 88). The methodology of this study is based on our interpretation of rhythmanalysis; as such, it is close to the ethnographic research approach. In ethnography, the researcher engages in the lives of the researched and completes the scrutiny from the perception of the agencies that are the subject of the research (e.g., Ybema et al. 2009).

\section{Material and Methods}

Rhythmanalysis does not adhere to the systematic methods familiar to Western philosophy (Lefebvre 2004; Frank 2019). Rather than being a weakness, this is the strength of rhythmanalysis because it poses a new way of knowing and creating knowledge (Lefebvre 2004; Frank 2019; Lyon 2019). As dynamic processes, rhythms do not have clear start or end points but are incomplete and in continuous flux (Lefebvre 2004, p. 89). However, to determine empirical analyses of processes '(i)t is necessary to identify units of analysis that represent some internal coherence and constituency' (Ibert et al. 2015, p. 324). Therefore, to capture 
sufficient longitudinal data from the Zan-SDI project, our data collection (November 2015-August 2019) exceeded the actual duration of the project (2016-2018).

To gain a comprehensive view of the knowledge creation rhythms, we used data triangulation. A multi-strategy approach reduces the bias that any single method might have (Bryman 2016). Rather than being mutually exclusive, various methods are complementary and increase the reliability and validity of rhythmanalysis (Lyon 2019, pp. 75-76). The main body of material consists of participant-observation notes (including written and recorded field notes and photos) and 92 roughly 30-min interviews collected during four research periods in Zanzibar and three in Finland. The first author was also part of the project's internal WhatsApp messaging group. To observe project activities during the times of dispersion, we collected 11 electronic surveys with 103 responses, and the project plan and reports were included in the analysis as well. Lefebvre and rhythmanalysis defy strict step-by-step procedures and categorisations (Lefebvre 2004; Simonsen 2005; Frank 2019). Therefore, there was no structured observation sheet, and the focus of attention varied greatly during the material collection.

Analysis of the empirical material began already in the field and resembles a qualitative inductive approach - the meanings emerged from the material as we compiled, continuously explored and analysed the content of the various data sets. We made notes on people, objects, non-materialities, and physical-natural phenomena, and how they changed. The locations, timings, actions, and mobilities were noted, but more importantly - and as the body of material grew-attention was given to the causes and effects, relations, and especially the meanings given to different phenomena (i.e., verbal and gestural signals of opinion, emotion, or sensation). These formed various moments and observations that were written and described-and in many cases realised only in retrospect. Indeed, once grasped by the rhythms, the rhythmanalyst started to better discern the relations, qualities and hierarchies of rhythms. In addition to the common, deviations from the general were traced further in the analysis. During the project development, not only an outline of the overall project pattern but also its intricacies became more lucid.

Living and constantly 'listening', seeking and understanding the rhythms (Lefebvre 2004, pp. 88-89) and writing, replaying, grouping, condensing and re-writing the notes into interdependent or tangential moments preceded the restored story of Zan-SDI, which we will elaborate in the next section. Our findings are well grounded in the extensive interview, participatory-observation and questionnaire material. Following rhythmanalytical and ethnographical principles, the results should be considered as a unique and fleeting description that the rhythmanalyst was able to grasp whilst interacting with rhythms and-as such—also a powerful synthesis derived from the multiform material and its knowledgeable interpretation. 


\section{Knowledge Creation Rhythms in the Zan-SDI Project}

\section{Improved Skills, Increased Understanding and Networking}

In broad terms, the project reached its goals: geospatial skills and the development and maintenance of NSDI, and the management of the coastal and marine environment were improved in Zanzibar, but not to the extent initially planned and desired. Disappointments and uncertainties were encountered throughout the project, but we begin rather by analysing what kind of knowledge creation was achieved.

Most of the partnerships within the consortium were established during the project. Not only was the partnership between the Finns and Zanzibarians new, but most of the country-specific subgroups had no experience of intensive collaboration with each other. In addition, local contexts including cultural and organisational practices in both countries were initially unfamiliar to most of the participants. Those from Zanzibar had worked in several development cooperation projects, but for the Finns this experience varied and was limited regarding Sub-Saharan Africa. Furthermore, the project composition and the issues covered were manifold and complex.

It is therefore unsurprising that the most efficient and extensive knowledge creation involved learning to know each other and work together and understanding how the project would be accomplished. The participants had to establish the routines of their joint temporary organisation, Zan-SDI, because the project could not proceed according to plan until common practices evolved. For the Finns, an important learning process concerned adjusting their analytical knowledge to the local rhythms, as one Finnish project member explained in a questionnaire response (August 2019):

The project concretised some vague thoughts I had before: Our practices cannot be implemented as such in Zanzibar, but solutions have to be compatible with local conditions.

For Zanzibarians, learning concerned mostly minor but fundamental improvements, such as better skills in information technology (IT) and storing documents. The most significant improvements were associated with people's capabilities and organisations' routines, such as managing a new geographic information system (GIS) application and being able to learn more about it independently.

However, training attendance and levels of expertise in the Zan-SDI core issues varied. Thus, knowledge creation was sporadic, and the benefits were unevenly spread. Moreover, the Finns were not initially prepared for this variety and their efforts were occasionally misplaced. Due to this same diversity, however, smatterings of knowledge and awareness of the core issues were distributed broadly within the organisations, as the following interviewee exemplifies:

Before (...) I was the one who knows how to operate the GIS applications, but nobody cared about me: what I knew, what I was doing. (...) Zan-SDI project made people to be aware of what GIS is, what the importance of GIS is: who I am and what my importance is. (Zanzibarian project member, December 2018) 
In the following section, we provide a more in-depth scrutiny of how knowledge was created during the project.

\section{Learning (in) the Interplay of People, Nature and Objects}

Whereas some rhythms entail stability and consistency to a place, others prompt change and even arrhythmia (Edensor 2010c, p. 3). For instance, seasonal rhythms such as darkness, cold and the lack of additional social rhythms may efficiently isolate people to work in some places (Ojala and Hautala 2019). In Zanzibar and Finland, however, local rhythms also distracted from the formation of a focused knowledge creation ensemble and the (re)production of new routines. Especially in Zanzibar, most of the excess rhythms (e.g., heat, noise, power cuts and protozoa) disrupted ongoing and planned activities. Local distractions were indeed so forceful that simply establishing an e-conference connection was a continual challenge even for the project's IT experts. Communication by e-mail did not work well either, and eventually WhatsApp became the most reliable channel for communication.

The rhythm of events in Zan-SDI varied between waiting and hurrying and reaching and losing the moment of co-presence as the ensemble kept dissolving due to arrhythmias. Both the Finns and Zanzibarians referred to 'Africa time' when characterising project activities. Schedules rarely held, and the irregular attendance caused frustration and disappointment amongst the Finns but also amongst the Zanzibarians, who felt they had to apologise. However, arriving late or being absent did not necessarily signal a lack of interest. The more the Finns experienced the everyday ensembles in Zanzibar, the more they understood how filled with all kinds of distractions and commitments they are, ranging from failing cars, traffic jams and overheating instruments to sudden health problems, issues in the (extended) family and natural disasters such as floods. These distractions derived not only from people and their behaviour but also from objects, the physical-natural environment, poverty, inefficient organisational routines and practices and, more importantly, combinations of these. Distractions were frequent, partially overlapping, and often resulting in a domino effect that hampered the progress of the project. Lefebvre (2004, p. 75) remarks that objects are also consumers of time. Indeed, the various arrhythmias became actants in the project and consumed the limited worktime allocated for it.

Also, the Finns were personally and negatively impacted by the everyday rhythms in Zanzibar. At times they were exhausted by the heat or absent for instance due to illness. However, towards the end of the project they learned to relax, improvise and adapt - to the extent that they started deliberately arriving late and changing plans on the way. These adjustments were necessary for achieving progress. Based on Lefebvre (2004, pp. 22, 39), the Finns needed to be 'broken in' and attached to the local conditions before they could promote change. The increasing and largely embodied understanding of the spatial, temporal and social configurations had a huge impact on how the practices (and the project) were lived and perceived.

Visits to Finland were rare, but they-and even withdrawal from the busy and cramped offices to a serene hotel area in Zanzibar-enabled similar practice-based 
and embodied learning. Here, the Zanzibarians were able to experience undisturbed moments of work, focus and co-presence. The visits to Finland and peer organisations also demonstrated how things could be in relation to good governance and data management. Although rhythms are most evident in the case of arrhythmia and disruption (Lefebvre 2004, p. 21), our empirical evidence indicates that also a temporary release from suppressing rhythms leads to acknowledging them.

Interview, questionnaire and observation material revealed that the number of organisations and participants in the project was considered to be substantial. Withdrawing from normal everyday routines enhanced the creation of eurhythmia amongst the various stakeholders. Although the hosts in either country were more dependent on their normal routines, those who withdrew together from their everyday life experienced intensive interaction and buzz during the visits. One of the interviewed Zanzibarian project members (December 2018) explains the positive impact:

In the past $(\ldots)$ we felt that it is not possible or easy for departments to come together (...) working, collaborating (...). But after we went to Finland and came back, I have seen some changes. Now (...) we are communicating and we seek assistance from each other. That kind of things never happened before.

Besides absorption into the Zan-SDI issues and places, the visits enabled social cohesion between the project partners. Given the cultural differences and newness of the partnership, the eurhythmia between the Finns and Zanzibarians was exceptional. Already in 2016, participants from both countries used words such as 'family' and 'friendship' in their general discussions, questionnaire responses and our one-on-one conversations to describe the collaboration. When dispersed, this eurhythmia was sustained through communication via WhatsApp; occasionally, the thread bustled with emoji and insider jokes.

\section{Unknown and Weathered Knowledge}

Next, we broach a more uncertain but also highly specific, important part of the rhythmanalytical work: interpreting the 'excess' from our ethnographic observation—or, as Lefebvre (2004, p. 19) explains it:

(A rhythmanalyst) will be attentive, but not only to the words or pieces of information, the confessions and confidences (...). He will listen to the world, and above all to what are disdainfully called noises, which are said without meaning, and to murmurs [rumours], full of meaning - and finally he will listen to silences.

During our observation we were able to discern some 'murmurs,' pay attention to comments made in passing, and perceive a few meaningful 'silences' and knowledge considered 'weathered' or known only to a few of the project partners. When restrained and diplomatic behaviour are commonly maintained in development cooperation and other inter-sociocultural environments (Amutabi 2013), acknowledging the silences reveals a lot about them. 
Although the main partnerships in the project were new, the initiation of the project derived from a long-term collaboration between some actors in Zanzibar and the University of Turku. Their presence in the Zan-SDI ensemble brought consistency and eurhythmia to the whole project; these actants acted as knowledge brokers and intermediaries throughout. Without their contextual understanding and diplomacy, the plan would have been even more ambitious and the foreign rhythms more incomprehensible. They already had an understanding of the rhythms in both countries that the others were still learning. Interactions with the intermediaries formed an important buffer and learning zone, which prevented or mitigated many arrhythmias.

During their visits, the Finns realised fairly soon that their expectations of the existing SDI in Zanzibar were too high. Combined with reports and descriptions from earlier projects, their initial visits had created unrealistic impressions of the current situation. Simply put, the project plan and activities did not coincide with reality. As one Finn aptly commented during an informal discussion, even if the state of the SDI had been as described, it had 'weathered' since then. Without the resources to maintain skills and knowledge, much had been forgotten, and even the technological devices had deteriorated in the heat and humidity before ZanSDI began. Some participants informally shared their belief that if the plan had been more simplistic — and thus more reasonable — the project very likely would not have been funded. Moreover, due to the scarcity of visits, the newness of the partnership and the funder's policies, it was difficult to understand the circumstances and then to try to re-orientate the practices.

Indeed, weathering of knowledge also occurred during the Zan-SDI project. Already in 2016, participants in both countries realised that efficient teaching and learning would not happen unless more resources and workhours were allocated. The visits were short and sparsely set over a period too long to sustain development. Moreover, the ensembles, including the circumstances and participating actants, kept changing. For instance, in the middle of the project the marine team encountered a major drawback because the corresponding team had basically evaporated. Only one person was left, as the others' life circumstances had changed. The situation was frustrating as everything that had been taught was now considered lost. Eventually, with improvisation and adjustments a practical solution was found. An interesting aspect that emerged was that one participant had left the project mainly thanks to Zan-SDI, using the knowledge acquired to get a study position abroad. What was initially considered a drawback now appears as an important developmental impact.

Many murmurs amongst the Zanzibarians were related to the new type of development cooperation. As governments in developing countries depend a great deal on intergovernmental financing, their routines and practices are shaped to accommodate it. With a very different approach (minimal financial and material support for Zanzibar), Zan-SDI did not succeed in convincing all superiors or even project participants of its importance and securing workhours for the project; other tasks and projects with more resources often supplanted it. For these reasons and the difficulties with online communication, it was mainly the 17 visits that brought the project participants together and enabled progress. 
Many critical issues remained unnoticed due to the partners' different everyday lives and the newness of the partnership. For instance, at the end of the last visit in 2018, the Finnish team came to realise a very significant fact that appeared only through a conversation between the Finnish and Zanzibarian intermediaries: there were no functional computers in one department, yet the training had already been done. This kind of ignorance also hampered Zan-SDI more broadly, as explained by a Finnish project member (August 2019):

(We) did not understand the realities of Zanzibar. (...) We did not expect that the level of map reading was so low, and we did not realise that some of the partners had never used a computer before. Thus, the computer training, and the way things were taught in the sea, were all in vain.

This quote not only reflects the steep learning curve that took place with regard to local circumstances, but also the challenges of projects based on capacity building but allocated insufficient resources to support the local infrastructure or map and update the baseline.

By the end of the project, the Finns felt that working in Zan-SDI had deepened their expertise. Their capacity to adapt their skills to different contexts had grown. They had gained international experience, collected material for further research and formed new networks. The Zanzibarians found this question more difficult to address when asked about reciprocity and how the project had benefited their Finnish partners. Through our research, we also found that the Zanzibarians had played a discreet but important role in supporting the project's progress. Before becoming adjusted to the local rhythms in Zanzibar, the Finns often seemed anxious. Many Zanzibarians mitigated these situations with humour, enthusiasm or apologies; previous international projects had taught them how to alleviate such inconveniences. It is crucial to elaborate these findings further, as acknowledging reciprocal learning, utility and support would help equalise the often-asymmetrical power balance in development cooperation (Lauer and Owusu 2016).

Finally, we revert to the weathering of knowledge. Despite the perceived setbacks, the Zan-SDI project succeeded in several ways. New contacts between organisations, trust, and social cohesion were built. Joint practices and routines were established, and, as the project went on, its importance and potential were better understood. The SDI capacity was improved, and the praxis for marine spatial planning was initiated in Zanzibar. Moreover, the partnership became firm. On the last day of the final visit in 2018, a Finnish group leader said, 'Well, it seems now that we are colleagues. Finally, we have reached that point. It seems that it is not as if we come from above to say how things are supposed to be done.' In the end, the true momentum of the project was still emerging. Despite the will, the need and several attempts, continued funding for the project was not granted. Without it, the created knowledge, capacity, new networks and potential is likely to weather away, again. In the next section, we position these dynamics of knowledge creation processes in the broader ensembles of which the Zan-SDI project was a part. 


\section{Discussion and Conclusion}

Through its rhythmanalytical approach, this research contributes to the need to enhance our understanding of knowledge creation and capacity-building processes in an expert-expert collaboration, which is a growing trend in contemporary development cooperation. Whilst the role of new actors, knowledge, resources and technology in international development dynamics is elaborated, the new framework of development and related processes has become far more complex and intricate. To scrutinise these complicated processes, novel in-depth research strategies are needed, and, in this study, we applied the rhythmanalytical approach.

To answer our first research question - through what kinds of rhythms is knowledge created in the Zan-SDI project-we discovered various knowledge creation rhythms. They were formed in the interaction of people, places and objects that all became actants of the knowledge creation processes and were affected by them. In Zan-SDI, most knowledge creation rhythms were sporadic, porous, and weathering due to the distractions caused by the local socio-material environment, especially in Zanzibar. Consequently, the periods spent together and the resources allocated for the project were too sparse for ideal progress. The arrhythmias both restricted and directed the project in various ways and consumed the limited operational time available.

Due to the discrepancies, the Finnish experts' limited understanding of Zanzibar, and the Zanzibarians' varied participation and skills in the project's core issues, the most efficient knowledge creation concerned the project ensemble itself. This knowledge about the partners, places, practices and limitations had to be created before the project objectives and eurhythmic knowledge creation rhythm could be achieved. It had to be created through embodied encounters and interactions with the several rhythms within the project and those infiltrating and interfering with it. Indeed, the local rhythms in both countries were an important subject of learning, and the increasing knowledge about the project contributed to the eurhythmia. For instance, before becoming accustomed to the everyday reality of the project, the Finns were burdened by the arrhythmias and unable to work in the most appropriate manner.

Although the Zan-SDI project scheme directed the knowledge creation endeavours and bundled the related people, places and objects together, the project took shape in the lived and partially unpredicted presences-in the interactions of the people, objects and the (social and material) environment. In a developing regime, such as Zanzibar, everyday practices are especially vulnerable to various arrhythmias ranging from political twists to failing equipment and abdominal diseases. The rhythms are entangled, vulnerable and highly dependent on each other: if an arrhythmia occurs somewhere, several ensembles may tumble. Understanding and working in these circumstances is demanding, especially for foreign experts with little to no previous experience of development cooperation or what local arrhythmias might mean. Like Jones and Warren (2016) and Dakka and Wade (2019), our research shows that most of the unnecessary arrhythmia, stress and inconveniences arise from productivity demands and time constraints that are detached from the 
lived reality. The Zan-SDI participants had to strive continuously to bridge the gaps and discrepancies between the conceived (e.g., plans and objectives) and the lived reality. Whereas Nicolini (2009) and Cunha and Clegg (2019) note that routines are always partially improvised, we can add that establishing and realising routines in fluid vulnerable contexts require a high level of improvisation and the permission and resources to do so.

Intentional adjustments are always required when reproducing or altering organisational patterns and routines (Feldman 2016). Transferring routines between very dissimilar organisations (Boe-Lillegraven 2019) and without cognitive proximity is particularly difficult (Hautala and Jauhiainen 2015). In new partnerships in development cooperation, these efforts and dissimilarities are very demanding due to a lack of resources, frequent distractions and vast geographical, cultural and cognitive distances. However, what prevented the Zan-SDI project ensemble from collapsing were the good relations that formed between the new partners and the presence of a few experienced intermediaries who had well-established relations and an in-depth understanding of the praxis in both contexts.

The above concepts on the weathering of knowledge and the importance of building personal relations and understanding the contexts in which the project operates all call for a long-term basis, sufficient resources and flexibility in development cooperation. Pure capacity building may direct insufficient funding to mapping the baseline and ensuring that the local infrastructure is able to support the project's activities. Moreover, even a well-conducted baseline may quickly become outdated in precarious conditions. Although the reciprocal learning and mainly non-material support of the Zan-SDI project was capable of changing the patterns to some extent, much of its potential remained unrealised without sufficient amounts of allocated time and financial or material support. Our results highlight that the project structure and related bureaucracy require flexibility in order that development projects may be capable of responding to actual and changing development needs.

Projects are considered to have a beginning and an end date, but, as rhythmanalysis discloses, processes rarely adhere to these artificial limits. Zan-SDI funding and activities ended before the momentum was reached. Hence, the knowledge and potential achieved are at a great risk of weathering away before a similar project is launched, perhaps with new actors yet again. To reach and support a long-term development impact and knowledge creation, the decisions and project funding criteria need to be based on insightful data that discerns the feasibility and importance of (continuation) funding, and on an understanding that acknowledges the everyday economic, social and political distortions in global development that the projects are trying to alleviate.

Our second research question concerned the potential that rhythmanalysis has for studying knowledge creation processes in development cooperation. We consider it an original qualitative approach to development studies. Rhythmanalysis brings embodiment and the role of non-human materiality into the foreground. It emphasises the corporeal experience and the unique and changing local socio-material contexts. Focus on rhythms enabled us to deepen our analysis of the social, material and non-material assemblages of a development project, especially from the interrelated spatial and temporal perspectives. In our study, rhythmanalysis, with 
its non-restrictive and flexible framework and encouragement toward an intensive co-presence, proved capable of detecting various important details, linkages and processes that would have otherwise been missed. Our study showed that knowledge creation processes, even in high-level institutions, are messy, complex and vulnerable to various incidents. The chosen methodological strategy allowed us to pay attention to the frequent or occasional arrhythmias that impeded progress as well as the small, additional or serendipitous development impacts. They could not have been measured with any univocal quantitative metre or simplistic qualitative research practices, such as a scarce number of interviews.

However, the ambiguity of rhythmanalysis is also a limitation of this study, as it made the research labour-intensive and complex. Becoming a rhythmanalyst is an ongoing process in itself (Lefebvre 2004, p. 22), and the authors are well aware of the limitations and generalisations of this single research. Whilst we definitely agree with Olsen (2019) that holistic and mixed-method approaches are needed to evaluate the complex processes in development cooperation, we also agree with Gaarder (2019) that clear, cost-effective and replicable methods are necessary as well. Rhythmanalysis provided a holistic yet detailed view on the Zan-SDI project. The findings also indicate what should be studied further with different methods and acknowledged when planning, implementing and evaluating the projects.

Lastly, despite our endeavour to obtain as balanced a view as possible, the empirical material emphasises the Finnish-or Global-Northern-perspective. For the Finnish authors, access to this ensemble was effortless compared to that in Zanzibar. However, as we are not experts in SDI and marine planning, it was easy to understand the difficulties absorbing the analytical information. Furthermore, neither the Finns' nor the Zanzibarians' ensemble was a homogenous group. Individuals' opinions and knowledge creation experiences are distinct, and this diversity within ensembles should be studied more carefully to avoid juxtaposition.

Acknowledgements We are truly grateful to all the Zan-SDI actors, MSc Anni Laitinen, and everyone else who took part in our research. On behalf of all the authors, the corresponding author states that there is no conflict of interest.

Funding This work was partly funded by Academy of Finland (Grant Number 259078) and Geography Section of the University of Turku. Open access funding provided by University of Turku (UTU) including Turku University Central Hospital.

Open Access This article is licensed under a Creative Commons Attribution 4.0 International License, which permits use, sharing, adaptation, distribution and reproduction in any medium or format, as long as you give appropriate credit to the original author(s) and the source, provide a link to the Creative Commons licence, and indicate if changes were made. The images or other third party material in this article are included in the article's Creative Commons licence, unless indicated otherwise in a credit line to the material. If material is not included in the article's Creative Commons licence and your intended use is not permitted by statutory regulation or exceeds the permitted use, you will need to obtain permission directly from the copyright holder. To view a copy of this licence, visit http://creativecommons.org/licen ses/by/4.0/. 


\section{References}

Alhadeff-Jones, M. 2019. Beyond space and time - Conceiving the rhythmic configurations of adult education through Lefebvre's rhythmanalysis. Zeitschrift für Weiterbildungsforschung 42 (2): 165-181.

Amutabi, M.N. 2013. The NGO factor in Africa: The case of arrested development in Kenya. New York: Routledge.

Ancori, B., A. Bureth, and P. Cohendet. 2000. The economics of knowledge: The debate about codification and tacit knowledge. Industrial and Corporate Change 9 (2): 255-287.

Asheim, B.T., and L. Coenen. 2006. Contextualising regional innovation systems in a globalising learning economy: On knowledge bases and institutional frameworks. The Journal of Technology Transfer 31 (1): 163-173.

Bathelt, H., A. Malmberg, and P. Maskell. 2004. Clusters and knowledge: Local buzz, global pipelines and the process of knowledge creation. Progress in Human Geography 28 (1): 31-56.

Bathelt, H., and S. Henn. 2014. The geographies of knowledge transfers over distance: toward a typology. Environment and Planning A 46 (6): 1403-1424.

Boe-Lillegraven, S. 2019. Transferring routines across multiple boundaries: A flexible approach. In Routine dynamics in action: Replication and transformation, eds. M. Feldman, L. D’Aderio, K. Dittrich and P. Jarzabkowski, vol. 61, 31-53. Research in the Sociology of Organizations.

Bryman, A. 2016. Social research methods. Oxford: Oxford University Press.

Chen, Y. 2018. Practicing rhythmanalysis: Theories and methodologies. London: Rowman and Littlefield International.

Cohen, W.M., and D.A. Levinthal. 1990. Absorptive capacity: A new perspective on learning and innovation. Administrative Science Quarterly 35 (1): 128-152.

Cunha, M.P., and S. Clegg. 2019. Improvisation in the learning organisation: A defense of the infraordinary. The Learning Organization 26 (3): 238-251.

Dakka, F., and A. Wade. 2019. Writing time: A rhythmic analysis of contemporary academic writing. Higher Education Research \& Development 38 (1): 185-197.

Drucker, P. 1993. Post-capitalist society. New York: HarperBusiness.

Edensor, T., ed. 2010a. Geographies of rhythm. Farnham, UK: Ashgate.

Edensor, T. 2010b. Walking in rhythms: Place, regulation, style and the flow of experience. Visual Studies 25 (1): 69-79.

Edensor, T. 2010c. Introduction: Thinking about rhythm and space. In Geographies of rhythm, ed. T. Edensor, 1-18. Farnham, UK: Ashgate.

ESRI. 2010. Spatial Data Infrastructure. A Collaborative Network. https://www.esri.com/library/broch ures/pdfs/spatial-data-infrastructure.pdf.

Feldman, M., B. Pentland, L. D’Adderio, and N. Lazaric. 2016. Beyond routines as things: Introduction to the special issue on routine dynamics. Organization Science 27 (3): 505-513.

Fejerskova, A.M., E. Lundsgaardea, and S. Cold-Ravnkildea. 2017. Recasting the "new actors in development" research agenda. The European Journal of Development Research 29 (5): 1070-1085.

Flower, J. 2015. The international integrated reporting council: A story of failure. Critical Perspectives on Accounting 27: 1-17.

Frank, S. 2019. Rhythms at sea: Lefebvre and maritime fiction. In: Rhythms now. Henri Lefebvre's rhythmanalysis revisited, eds. S.L. Christiansen and M. Gebauer, 159-188. Aalborg: Aalborg Universitetsforlag.

Gaarder, M.A. 2019. Commentary to "bridging to action requires mixed methods, not only randomised control trials." The European Journal of Development Research 31: 169-173.

Gertler, M. 2003. Tacit knowledge and the economic geography of context, or the undefinable tacitness of being (there). Journal of Economic Geography 3 (1): 75-99.

Gibson, C., ed. 2012. Creativity in peripheral areas: Redefining the creative industries. Oxon: Routledge.

Glückler, J. 2014. How controversial innovation succeeds in the periphery? A network perspective of BASF Argentina. Journal of Economic Geography 14 (5): 903-927.

Gore, C. 2013. The new development cooperation landscape: Actors, approaches, architecture. Journal of International Development 25 (6): 769-786.

Grabher, G., and O. Ibert. 2014. Distance as asset? Knowledge collaboration in hybrid virtual communities. Journal of Economic Geography 14 (1): 97-123. 
Grabher, G., A. Melchior, B. Schiemer, E. Schüßler, and J. Sydow. 2018. From being there to being aware: Confronting geographical and sociological imaginations of copresence. Environment and Planning A: Economy and Space 50 (1): 245-255.

Gärtner, C. 2013. Cognition, knowing and learning in the flesh: Six views on embodied knowing in organisation studies. Scandinavian Journal of Management 29: 338-352.

Hautala, J. 2015. Interaction in the artistic knowledge creation process: The case of artists in Finnish Lapland. Geoforum 65: 351-362.

Hautala, J. 2018. Now together, next apart: Knowledge creation processes through repeated geographical dispersion. Geografiska Annaler: Series B, Human Geography 100 (3): 220-243.

Hautala, J., and J. Jauhiainen. 2014. Spatio-temporal processes of knowledge creation. Research Policy 43 (4): 655-668.

Hautala, J., and M. Höyssä. 2017. Knowledge rationales in human geography: Economic, policy, empowerment, and methodological. Norsk Geografisk Tidsskrift - Norwegian Journal of Geography 71 (5): 269-287.

Hooli, L.J., and J.S. Jauhiainen. 2018. Building an innovation system and indigenous knowledge in Namibia. African Journal of Science, Technology, Innovation and Development 10 (2): 183-196.

Horner, R., and D. Hulme. 2019. From international to global development: New geographies of 21st century development. Development and Change 50 (2): 347-378.

Ibert, O. 2007. Towards a geography of knowledge creation: The ambivalences between 'knowledge as an object' and "knowing in practice." Regional Studies 41 (1): 103-114.

Ibert, O., J. Hautala, and J. Jauhiainen. 2015. From cluster to process: New economic geographic perspectives on practices of knowledge creation. Geoforum; Journal of Physical, Human, and Regional Geosciences 65: 323-327.

ICI, Institutional Cooperation Instrument. 2012. Manual and recommended best practices. Finland: Ministry for Foreign Affairs.

Janus, H., S. Klingebiel, and S. Paulo. 2015. Beyond aid: A conceptual perspective on the transformation of development cooperation. Journal of International Development 27 (2): 155-169.

Jauhiainen, J.S., and L. Hooli. 2019. Innovation for development in Africa. New York: Routledge.

Jones, H., N. Jones, L. Shaxson, and D. Walker. 2013. Knowledge, policy and power in international development: A practical framework for improving policy. London: ODI.

Jones, P., and S. Warren. 2016. Time, rhythm and the creative economy. Transactions of the Institute of British Geographers 41: 286-296.

Lauer, S., and F. Owusu. 2016. Learning and power in international development partnerships: A case study of Iowan farmers in Uganda. Community Development Journal 51 (3): 382-400.

Lefebvre, H. 2004. Rhythmanalysis: Space, Time and Everyday Life. New York: Continuum.

Lefebvre, H. 1991. The production of space. Oxford: Blackwell Publishing.

Lewis, D. 2019. "Big D'and" little d': Two types of twenty-first century development? Third World Quarterly 40 (11): 1957-1975.

Little, T.A., and A.V. Deokar. 2016. Understanding knowledge creation in the context of knowledgeintensive business processes. Journal of Knowledge Management 20 (5): 858-879.

Livingstone, D.N. 2003. Putting science in its place: Geographies of scientific knowledge. Chicago: University of Chicago Press.

Lyon, D. 2019. What is rhythmanalysis? London: Bloomsbury.

Ministry for Foreign Affairs of Finland. 2017. Country Strategy for Development Cooperation. Tanzania 2016-2019.

Nicolini, D. 2009. Zooming in and out: studying practices by switching theoretical lenses and trailing connections. Organisation Studies 30 (12): 1391-1418.

Nguyen-Duc, A., D.S. Cruzes, and R. Conradi. 2015. The impact of global dispersion on coordination, team performance and software quality-A systematic literature review. Information and Software Technology 57: 277-294.

Nonaka, I., and H. Takeuchi. 1995. The knowledge-creating company: How Japanese companies create the dynamics of innovation. Oxford: Oxford University Press.

Ojala, M.L., and J. Hautala. 2019. Knowledge creation rhythms of a science project, in and beyond remote Ny-Ålesund in the Arctic. Polar Geography 42 (1): 1-17.

Olsen, W. 2019. Bridging to action requires mixed methods, not only randomised control trials. The European Journal of Development Research 31 (2): 139-162.

Parrilli, M.D., and H.A. Heras. 2016. STI and DUI innovation modes: Scientific-technological and context-specific nuances. Research Policy 45 (4): 747-756. 
Popper, K. 2005. The logic of scientific discovery. London: Routledge.

Powell, M., and S. Cummings. 2019. Making the most of knowledge for development and development studies. In Building development studies for the New Millennium, 163-187. Cham: Palgrave Macmillan.

Rocha, H. 2013. Dominant development paradigms: A review and integration. Journal of Markets \& Morality 16 (1): 7-24.

Schillings, P., and A. Wickeren. 2015. Towards a material and spatial history of knowledge production: An introduction. Historical Social Research 40 (1): 203-218.

Shearmur, R., C. Carrincazeaux, and D. Doloreux, eds. 2016. Handbook on the geographies of innovation. Northampton, MA: Edward Elgar Publishing.

Shields, R. 1998. Lefebvre, love and struggle. Spatial dialectics. London: Routledge.

Simonsen, K. 2005. Bodies, sensations, space and time: The contribution from Henri Lefebvre. Geographic Annalen 87 (1): 1-14.

Strati, A. 2007. Sensible knowledge and practice-based learning. Management Learning 38 (1): 61-77.

Sydow, J., and T. Braun. 2018. Projects as temporary organisations: An agenda for further theorising the interorganizational dimension. International Journal of Project Management 36: 4-11.

Syring, D. 2009. La Vida Matizada: Time sense, everyday rhythms, and globalised ideas of work. Anthropology and Humanism 34 (2): 119-142.

Turner, J.R., and R. Müller. 2003. On the nature of the project as a temporary organisation. International Journal of Project Management 21: 1-8.

UN (United Nations). 2015. Transforming our world: The 2030 agenda for sustainable development. New York: United Nations.

UN (United Nations). 2019. United Nation's web-based data service. http://data.un.org/. Accessed 10 December 2019.

Vallejo, B., and U. Wehn. 2016. Capacity development evaluation: The challenge of the results agenda and measuring return on investment in the global south. World Development 79: 1-13.

Walz, J., and V. Ramachandran, V. 2011. Brave new world: A literature review of emerging donors and the changing nature of foreign assistance. Center for Global Development Working Paper (273).

van Veen, S.C., J.G. Bunders, and B.J. Regeer. 2013. Mutual learning for knowledge co-creation about disability inclusive development programmes and practice. Knowledge Management for Development Journal 9 (2): 105-124.

Viteritti, A. 2013. It's the body (that does it)! The production of knowledge through body in scientific learning practice. Scandinavian Journal of Management 29: 367-376.

Wright, A. 2019. Embodied organizational routines: Explicating a practice understanding. Journal of Management Inquiry 28 (2): 153-165.

Wunderlich, F.M. 2008. Walking and rhythmicity: Sensing urban space. Journal of Urban Design 13 (1): $125-139$.

Ybema, S., and F. Kamsteeg. 2009. Making the familiar strange: A Case for disengaged organisational ethnography. In Organisational ethnography: Studying the complexities of everyday life, 101-119.

Zan-SDI. 2015. Project document, National Spatial Data Infrastructure for Integrated Coastal and Marine Spatial Planning in Zanzibar (ZAN-SDI). The Finnish Environment Institute in cooperation with Zanzibar Commission for Lands.

Zan-SDI. 2019. Completion report, National Spatial Data Infrastructure for Integrated Coastal and Marine Spatial Planning in Zanzibar (ZAN-SDI). The Finnish Environment Institute, the National Land Survey of Finland and University of Turku in cooperation with Department of Urban and Rural Planning, Zanzibar.

Publisher's Note Springer Nature remains neutral with regard to jurisdictional claims in published maps and institutional affiliations. 